\title{
SOBRE EL FIN Y LA FINALIDAD DEL UNIVERSO
}

\author{
Alfonso Pérez de Laborda \\ Universidad Eclesiástica de San Dámaso - Madrid
}

Del mismo modo que no me gusta hablar del duplo esencia/ existencia, por palabras demasiado abstractas que significan mucho menos de lo que a veces se piensa y que, al contrario, por el mero hecho de utilizarlas encierran un significado especial que no comparto; por idéntica razón, tampoco me ha gustado hablar de universo, mucho menos de Universo. Nos hace pensar que nosotros somos espectadores de ese universo, aunque sea con minúscula. Espectadores de ese espectáculo que nos encontramos estando al margen de él como seguros vicedioses, sin embargo, sin estar implicados en él hasta lo más profundo de lo que nos ha tocado ser. Espectadores que proceden con una mirada que conlleva como punto esencial el principio de objetividad. Es verdad que la ciencia habla de universo, incluso de Universo, queriendo entenderlo como una unidad regida toda ella por las mismas leyes, que conocemos ya o estamos conociendo, pero que, sin duda, con el tiempo conoceremos mejor. El universo, si se quiere el Universo, sería el conjunto de todo; el conjunto de todo lo grande, lo cósmico, por así decir, regido por las leyes de la física, y el conjunto de todo lo pequeño, lo que toca la vida, regido por la biología. En un caso y en el otro, nosotros, como pensadores científicos, estariamos fuera

1 Texto de la conferencia pronunciada dentro del ciclo "Fides et Ratio" sobre el "Fin del Universo", el 6 de Noviembre de 2014, en el Centro de Estudios Teológicos de Sevilla. 
del propio universo, al margen de él, revolando fuera de él, sus espectadores objetivos, quienes lo piensan, o al menos quienes buscan inquisitivamente esa objetividad, dando cuenta objetiva del gran espectáculo del mundo, Seriamos espectadores científicos de lo que son no más que puras objetividades, las cuales solo nos atañen en cuanto somos simples espectadores. Es verdad que nosotros en parte somos seres físicos y en parte seres biológicos, pues bien, deberemos ser tratados como tales donde convenga hacerlo, pero en esta visión universalista sobre el universo nosotros quedamos esencialmente fuera, puesto que, se dice, tenemos la capacidad de pensar sobre el conjunto del universo, o, si se prefiere, del Universo, con una razón de objetividades, objetividades científicas, objetividades que se valen del método científico, dicen: nosotros lo comprendemos y explicamos tal como el universo es. Ahora bien, actuando así, hemos quedado desencarnados; ninguna relación tenemos con el Universo fuera del propio pensamiento que lo piensa. Seríamos meros seres pensantes que piensan sobre él, pero que en nada estarían implicados profundamente con él; en nada estaríamos implicados encarnativamente con él. En nuestro rol de vicedioses, seríamos pensamiento activo que contempla pasivamente el Universo: porque nuestro papel es de enorme actividad pensante, sin duda, mas por completo pasivo en cuanto que no estamos implicados en él encarnativamente. Recuérdese la manera galileana de nuestra razón, no extensive, pero sí intensive, conocemos en toda su profundidad lo que estudiamos, y lo conocemos en toda su objetividad. Tenemos un conocimiento pleno del universo en cuanto que actuamos sobre él con nuestro pensamiento; con nuestra razón, por más que, es verdad, tiene todavia la relatividad de ser un conocimiento no completo. Muchos filósofos de las ciencias apuestan al futuro: conoceremos más y más hasta conocerlo todo por completo. El que llegó más lejos en esta manera de pensar, ya lo sabemos, fue Vladimir Illych Lenin: en el momento final del universo la humanidad en su conjunto lo habrá conocido todo; por eso, ya desde ahora podemos decir que no cabe lugar para el misterio: lo incomprensible, lo incognoscible no existe, o mejor, ya desde ahora podemos asegurar con certeza que todo es comprensible, que todo es cognoscible, y que llegará un día en que lo habremos conocido y comprendido todo. Cuando llegue el final, dentro de los años, siglos o milenios que sean, veremos que es así. ¡Profetas! En esta manera de ver las cosas, por tanto, 
el conocimiento no es cosa personal, tuya, mía, nuestra, sino de la especie, por más que hay entre nosotros algunos de los especialistas de esta especie que tienen la rara habilidad de saber ya desde su ahora lo que será en el su lejano entonces. Tienen la suerte de ser raros profetas que ven y saben lo que los demás no vemos ni sabemos; y ellos lo ven y lo saben con la certeza de su objetividad. Nótese, pues, que tengo por inaceptable racionalmente no aquello a lo que se refiere la palabra universo, incluso la palabra Universo, y lo que sabemos de él, sino el lugar en el que deberiamos nosotros ponerlos para mirarlo ${ }^{2}$.

Vamos a ver que las cosas sobre el fin y la finalidad son muy distintas si hablamos de universo, construido sobre el empleo inexorable del principio de objetividad, o si hablamos de mundo como vamos a hacer ahora. El universo seria, pues, todo lo que nosotros, como espectadores plantados en la objetividad, vemos como tal, como cuando vivimos dentro del duplo esencia/existencia: sería todo lo que decimos que existe. Haciéndolo así, mas parece que se nos está olvidando algo decisivo: nosotros nos movemos siempre en un ámbito de experiencialidad, y no en un ámbito impregnado de un empirismo que, decimos, va a las cosas mismas. Deberá tenerse en cuenta que esa existencia del universo lo es para nosotros, en cuanto que somos nosotros quienes lo contemplamos como tal fuera de nosotros mismos, con lo que seríamos sus espectadores. Por eso, como si fuéramos de la mano de algún físico extrañamente dotado, podríamos ir viendo en su objetividad todo lo que el Creador ha creado y el modo en el que lo ha hecho. Así, se piensa, lo comprenderiamos y lo explicaríamos todo. Y en lo que de física y de biología tenemos nosotros los espectadores de ese espectáculo que se representa ante nuestros ojos, estariamos incluidos en el propio universo, por lo que también seríamos comprendidos y explicados por completo. Nuestra mente científica, nuestro pensamiento científico sería quien todo lo comprende y todo lo explica por medio de las leyes y normas con que intensive y extensive lo veria, haciéndolo incluso

2 Los medievales, tomando la cosa desde antiguo y llegando más acá de ellos, hablaban con inteligencia de un macrocosmos y de un microcosmos, y eran muy conscientes del puesto intermedio e intermediario que nosotros jugábamos en esa disyunción. Pensaban que nosotros éramos los medieros entre uno y otro cosmos. 
mejor que el propio Dios creador, si tuviera algún sentido hablar de creación. Vemos que en esta manera de pensar tanto Dios como que sea Dios creador pierde toda su importancia, no sería sino el modo de contarnos que lo hemos de saber todo, porque lo hemos de dominar todo. Así pues, porque seguiría el desarrollo completo del universo, explicándomelo, tendría capacidad para hablar de su fin. Este fin, evidentemente, nada tendría de finalidad, sino que - utilizando el pensar de Newton de que la fuerza de atracción universal acabará dominando a la fuerza de expansión actual del propio universo- acontecería en un mero acabarse la cuerda, por lo que todo él se derramaría sobre sí mismo en increíble fragor. De no ser así porque como muchos piensan hoy la expansión será indefinida, el fin de todo será el perderse sin sentido en los espacios siderales. Ver una o la otra posibilidad es cuestión de cálculos cosmológicos muy precisos. En un caso, la destrucción final del todo fruto de una terrible implosión, que, quizá, podría dar origen a una nueva explosión inicial; en el otro, la destrucción final del todo como fruto del total desmigajamiento indefinido en el perderse en el espacio y en el tiempo infinitos las naves cósmicas en las que viajemos. En ninguno de los dos casos sería un final apetecible y con sentido para nosotros, ya que nada tendríamos que añadir a lo que comprendemos y explicamos del universo. Así pues, un final sin finalidad alguna. Un final sin fin.

Las cosas son muy distintas si hablamos de mundo, efectivamente, porque entonces mundo sería el conjunto de todo lo que hay con un haber material. Seria, pues, una palabra marcada, porque, siendo así, mundo no se referiría a todo lo que hay, a todo lo que existe, podriamos decir ahora sin problemas, sino solo a todo lo que hay con un haber creado. Cuando hablo de mundo, me refiero a un mundo creado por Dios creador. Tengo razones para ello. En la consideración de mundo, pues, estarían dichos ya dos pensamientos que no podríamos dejar fuera para considerarlo. En lo que hay expresamos una parte de eso que hay con un haber de creación; el mundo es en toda su amplitud y detalle lo que ha sido creado por Dios en el acto mismo de la creación, que luego sostiene de continuo con su providencia, $\mathrm{y}$, nosotros, hemos sido creados a su imagen y semejanza, como hemos resumido el pensamiento de lo que somos utilizando esa soberbia fórmula de las primeras página del Génesis. Quedaria una segunda consideración extremadamente importante: 
hay un hay que no es el hay de las cosas mundanales, es el hay del Dios creador e increado. En el diábolo al que de continuo me refiero, este hay sería el ámbito de Dios que tiene su vértice inferior en el espacio de más-allá que contiene al punto omega, y que es el creador y sostenedor del cono de abajo en el que se encuentra todo lo que tiene consistencia de hay mundanal; de todo lo que tiene haber de qué o quién mundanal, esto es, de todo lo que se da en la evolución creadora de la materia creada. De esta manera, las cosas en una filosofia de la carne se nos dan a la vista de modo totalmente distinto a si entramos en ellas por la consideración del universo, en el que no aparece el hecho creador y nosotros no ocupamos ningún papel de realidad carnal, sino el de meros vicedioses de puro entendimiento, porque en este caso, el entender no es sino cosa mental, de pura razón pura, puro encadenamiento de logicidades, mientras que en el otro el entender es cosa bien carnal, de pura razón de humedades. Alguien podría negar por entero lo que entiendo por mundo, por lo que nos encontrariamos en un batalla campal para ver si podemos decir que el mundo es creación o no lo es. Aquí, para seguir adelante, damos esa batalla por habida... y ganada. Toda una serie de razones filosóficas convergen hacia esa afirmación sobre el mundo, la última de las cuales es esta: en nuestro continuo preguntar racional sobre el mundo y sus cosas, de nuestra experiencia sobre él, nos encontramos siempre que este termina por darnos respuestas racionales a nuestras preguntas, respuestas que caben en nuestra experiencia, lo que nos lleva a considerar que la estructura del mundo tiene racionalidad, y una racionalidad semejante a la nuestra, pues de otro modo esas respuestas experienciales no podrian ser racionales, lo que, a su vez, provoca nuevas preguntas racionales por nuestra parte y respuestas racionales por la suya, y en donde nuestra experiencia sobre nosotros mismos y sobre las cosas del mundo crece incesantemente. Siendo así, llegamos a una última pregunta -algunos deciden que esas preguntas de ultimidades no hay que hacerlas, ¿quién nos lo impediria?-: ¿por qué hay siempre algo en nuestra experiencia en vez de encontrarnos que, finalmente, no hay nada en ella? Porque el mundo responde a nuestras preguntas racionales con respuestas que también son racionales. No tenemos razón alguna para presuponer que habrá preguntas sin respuesta porque se referirán ya, finalmente, a nonadas; nuestra experiencia siempre es positiva, siempre encuentra en lo que busca una 
razón de experiencia. Todas las preguntas que hacemos a nuestra experiencia del mundo han de tener respuesta que la acrecienten, aunque quizá nos ha de costar encontrarla. Nuestras preguntas, siempre preguntas de experiencia, y por tanto esa última pregunta, han de tener respuesta racional, porque esa es la presuposición de todo lo que es nuestra experiencia del conocimiento del mundo. Dada la experiencia que tenemos de la racionalidad de la creación y la que acompaña a nuestra mirada a ella, es de necesidad que nuestras preguntas montadas sobre nuestra húmeda razón experiencial obtengan respuestas a tenor de ella. Ya desde Leibniz, pues, la cuestión es clara: esto es así, porque el mundo es creación. Lo que nos ha llevado a un continuo discurrir desde el acto de creación en el que se da la materia en su continua evolución con sus cuatro internalidades.

Miramos al mundo, a la materia en su evolución creativa, y encontramos que somos nosotros el punto rojo de la evolución cósmica y biológica. Todo lo que ha llevado a la evolución del cosmos ha valido como propensión para que nosotros estemos ahora en donde estamos. Porque, por ejemplo, el mundo poco tiempo después de la explosión inicial se hizo transparente, pues bien, nosotros somos hijos de aquella transparencia del mundo, de ese ser transparente del mundo; de no haber sido así, nosotros no estariamos contándolo. Todo en la evolución del cosmos ha llevado a nosotros; a que nosotros estemos mirando al mundo, y a que seamos los únicos con esa capacidad de mirada cuajada de húmeda razón experiencial sobre el mundo, sobre los qué y los quiénes del mundo. La evolución creativa de la materia cósmica ha llevado a donde estamos. Y, también, todo en la evolución de la vida ha llevado a que nosotros estemos mirando el mundo de la manera tan especial con la que lo miramos, explicándolo, comprendiéndolo y platicando sobre él. Toda esa evolución creativa nos ha llevado a ser el punto rojo hacia el que todo converge. Punto rojo de la evolución, pues esta ha llevado a que nosotros miremos al mundo con mirada también racional. Tenemos una cualidad sorprendente y única en el mundo: somos logos, esto es, palabra, verbo, sermón. Por eso podemos platicar sobre el mundo y sobre todo lo que hay. Ningún otro hay mundanal lo hace. Vistas las cosas así, sin duda que podremos decir: nosotros somos la finalidad del mundo, no porque seamos los últimos seres que subsistirán todavía cuando 
llegue el final, seguramente ratas e insectos nos adelantan en esa cualidad, pero a ellos les falta la mirada, porque toda la evolución creativa de lo mundanal desde el acto de la creación lleva a la afirmación de nuestra mirada. Por eso afirmaremos que la finalidad del mundo es nuestra mirada. Mirada de belleza y de comprensión.

Así pues, nos encontramos mirando al mundo. Nuestra mirada es racional, con una razón experiencial de humedades. Lo contemplamos y quedamos prendados de su belleza, hasta el punto de que no es tontería decir que el mundo es el primer regalo que Dios creador nos hace. Porque la belleza con la que nos encontramos y que nosotros generamos de continuo en nuestra referencia a él también nosotros somos creadores de belleza- queda circunvalada por la belleza del mundo y, más allá todavía, por la belleza de todo lo que hay, de todo lo que es. La consideración de la belleza nos es aquello que nos acerca de mejor manera a la materialidad de nuestro ser de carne. Porque los instrumentos con los que nosotros la creamos los compramos en la droguería o en la cantera, cuando no en chatarrerias de hierros sobrantes y herrumbrados. Y de ahí nuestra creatividad es capaz de construir realidades ante las que exclamamos: ¡qué bellezai Así, la belleza, naciendo en la pura materialidad de donde la recogemos, nace en nuestras líneas de vida, agitadas por la suave suasión que estira de nosotros para que nos alleguemos a su espacio de más-allá — ¿o, quizá, a los otros espacios atractores que nos atraen al mal, en donde no se da ya connaturalidad de amor?-, espacio de más-allá en donde mora el punto omega, con su realidad carnal como la nuestra, pero, él, abierto a la belleza inconmensurable del ámbito de Dios en el cono de arriba. Por esto, podemos decir que el mundo es el primer regalo que Dios nos hace.

He dicho que el ámbito de Dios tiene un vértice en el espacio de más-allá que contiene al punto omega. Porque todas nuestras lineas de vida convergen por connaturalidad de carne al espacio en donde se encuentra ese punto. Convergen porque esa connaturalidad hace que seamos atraídos hacia él con suave suasión, connaturalidad de amor - pero, cuidado, ya lo sabemos, hay otros puntos atractores que nos alejan de ella, por eso el mal- Espacio de más-allá que en ese estirar de atracción se hace nuestro también, aunque sea el espacio en el que habita la carne 
del punto omega. Porque el punto omega en su mirada hacia el cono de abajo, viene de una línea de vida como la nuestra, que comparte como carne idéntica a la nuestra la naturaleza material evolutiva que nace con el acto de creación de lo que somos, con la capacidad de estirar de nosotros con suave suasión para que, allá, en aquel espacio del punto omega se nos done nuestro ser en plenitud. Este es el segundo y definitivo regalo que Dios nos hace, a nosotros, punto rojo de la creación que con él compartimos. Un espacio por el que el Espíritu de Dios se derrama a través del punto omega en nosotros y en todo ser mundanal que hay en el cono de abajo. De esta manera, todo en nosotros mira hacia ese pequeño espacio de arriba, espacio de más-allá en el que se encuentra la carne misma del punto omega, que bajó desde el ámbito de Dios, en el cono de arriba, para arrecoger en sí todas las propensiones que en nosotros y en todos los hayes mundanales nos dirigen por connaturalidad de amor hacia él, siempre proponiéndonos, nunca arrancándonos la voluntad de elección, ofreciéndonos la donación de nuestro ser en plenitud.

Por tanto, la finalidad del mundo creado, arrecogiéndonos a nosotros como punto rojo de la creación, es el punto omega; punto al que todo lo que hay mundanal tiende a converger. Porque, dice tan asombrosamente Pablo, la creación, expectante, está aguardando nuestra manifestación, para ser librada de la frustración del mal, de modo que la creación misma gime con dolores de parto, pero un día será librada de la esclavitud de la corrupción en la que ahora se halla, para entrar en la gloriosa libertad de las creaturas de Dios. La finalidad del mundo somos nosotros, punto rojo de la evolución cósmica y biológica, con su cúspide en el vértice de todo lo creado, el punto omega.

En cuanto al fin del mundo, excepto que lo vayamos destruyendo nosotros piedra a piedra hasta arrancar toda vida de la tierra, como hacemos tantas veces con demasiado énfasis, solo sé de él en sus realidades por las películas y series de televisión infinitas que nos predican cada día el inexorable final apocalíptico en el que, dicen, nos encontramos, de manera que nuestras carnes estén en continuo temblor ante quienes buscan captar nuestra voluntad y hacerse con el poder respecto a nosotros. Porque, para ellos, vivimos un apocalipsis en el que no cabe la esperanza. 
En cambio, para nosotros, sí cabe la esperanza. Y porque cabe la esperanza, aunque no sepamos nada de él, nos cabe pensar que todo el mundo de lo que hay terminará por arrecogerse también él en ese espacio de más-allá en el que se encuentra el punto omega al que nosotros nos hemos acercado, expectante de nuestra manifestación plena, para entrar también él en la plenitud del regalo que Dios nos hace en su belleza.

Cuál sea la finalidad del mundo es cosa muy importante para ver qué hagamos con él y cómo nos comportemos dentro de él. No así tratándose de un abstractamente objetivo universo desprovisto de finalidad, en cuyo caso no tendremos que comparar nuestra acción con algo que consideramos como inexistente, por lo que siempre estaremos más sueltos en nuestro hacer; nunca estaremos sujetos a un absoluto que prima incluso a todo pensamiento racional que no tienda hacia él. Si la finalidad del mundo tiene que ver con el punto rojo de la evolución cósmica y biológica, nosotros, que somos ese punto rojo, constituiremos un absoluto; un nosotros que contiene yoes, tús y ellos. De este modo, no podremos saltárnoslo con acciones que nos puedan parecer pertinentes dentro de ese universo abstractivo, pero que van contra el hecho absoluto de defender nuestra vida. Por eso, en nuestra acción deberemos atenernos a lo que es defender nuestra vida individual y colectiva. Y no bastaría con una defensa colectivista de la vida que se salte por encima la defensa de nuestra vida individual, porque el punto rojo no es una abstracción que señala una vida genérica, sino un punto bien cálido que señala la vida personal. Esto me parece esencial, de ahí que quiera ahora, para terminar con la cuestión de la finalidad, indicar caminos que parecerian tan alejados de lo que estamos diciendo acá en paginas tan abstractas, pero en los que nos enfrentamos al fin y a la finalidad del mundo, al fin y la finalidad de lo que somos, porque las cosas que pensamos siempre tienen incidencia en las que hacemos, de modo que no nos bastará con una defensa genérica de ese punto rojo, ya que nunca podremos aceptar todo aquello que vaya en contra de nuestro ser personal. Todo hacer nuestro deberá construirse en la esperanza de ser más de lo que vamos siendo, esperanza de un amejoramiento, y nunca en ser menos o destruir lo que somos, desesperanza de un apeoramiento, o hacer que lo que vamos siendo sea esperanzador solo para un grupo de personas, los poderosos, los dominantes, 
los que tienen una notable capacidad de convicción, olvidando la vida plena de quienes comparten con ellos el ser punto rojo de la evolución. Nadie puede, pues, taparse con esa manta en su propio provecho, olvidando y destruyendo como inexorables enemigos a quienes, dicen, no cabrian bajo ella y por eso no pueden contar para nada. La esperanza está vestida de respeto total a todos los que somos ese punto rojo de la evolución, sin que arramblemos con el derecho a decidir quién no forma parte de él, por lo que deberá ser destruido inexorablemente para dejar sitio a los poderosos. Y, cuidado, es tan absoluto lo dicho que no me valdría incluso aunque esos poderosos fueran una mayoría con votación democrática, si no se me arranca con violencia, yo tendría siempre el derecho y el deber del disenso.

Los tres ejemplos desgarradores que vienen a continuación servirán para que comprendamos este punto tan esencial de lo que he llamado la finalidad del mundo, pues esta finalidad no es cosa abstracta, sino que nos está señalando un comportamiento en la vida.

El papa Pablo VI publicó el 25 de julio de 1968 una encíclica que incendió el globo terráqueo entero, la Humanae vitae. No entro en discusión con las cuestiones prácticas que propugnaba, y que no han tenido mucho seguimiento, simplemente hago notar que fue un hito en las posturas que la Iglesia católica ha ido tomando desde entonces en lo que toca al matrimonio y la vida, mostrando que tiene cosas propias que decir sobre estas cuestiones decisivas. Sin la existencia de aquella encíclica, probablemente, como ha ocurrido en otros ámbitos, hubiera habido una gran rampa inclinada por la que se hubiera precipitado en el no tener nada propio que decir, como se ha visto de manera asombrosa en algunas Iglesias, sino el mero dejarse llevar por el gradiente, tan fuerte, de las opiniones públicas recibidas, haciendo, al parecer, de manera continuada, lo que se les ha ido diciendo. Sin aquella encíclica, de cierto que no hubiera existido el Sínodo sobre la familia de 2014 y 2015, con los resultados que alcance.

El inversor multimillonario Warren Buffet, uno de los hombres más ricos del mundo, ha donado muchos millones de dólares a organizaciones caritativas que propugnan y realizan el aborto en 
países africanos: él, como muchos, entienden que el aborto es el mejor método para evitar el hambre y la superpoblación. Curioso, en China han empleado durante decenios el aborto para conseguir un solo hijo de cada matrimonio de modo que la superpoblacion no les acogotara, y ahora están poco a poco y con gran prudencia volviéndose atrás de esa política. Con esto me encontré hace unos años en una visita a Puerto Carreño, en la esquina colombiana del río Orinoco: "En el otro [coche], una médica, Adelma, una odontóloga, Cristina, una enfermera, Nancy Gloria, y el chofer, Abigail, el dueño de la furgoneta. Las médicas salen toda la semana a recorrer asentamientos. Vuelven el viernes por la tarde, y todavía el sábado por la mañana trabajan desde las siete y media de la mañana. Admirable, pero lleno de problemas. Son de una compañía privada. Llevan una vida dura. Se hinchan, por ejemplo, a dar pastillas anticonceptivas, porque las tienen que dar, porque se las piden y porque si no las dan les echan de su trabajo, iqué hacer! Ellas son católicas".

Dos empresas multinacionales de entre las más importantes y productivas, Apple y Facebook, a las mujeres que trabajan con ellas proponen pagar la congelación de óvulos, guardándolos para cuando llegue un momento más conveniente en su trabajo, de modo que su carrera no quede cortada con gestaciones que lleguen en mal momento, no pudiendo por ello dar la importancia que tienen en el trabajo que realizan.

¿No estamos tocando acá el meollo mismo del fin y de la finalidad del mundo? 